\title{
Clinical predictors of right upper paraesophageal lymph node metastasis from papillary thyroid carcinoma
}

\author{
Yong-Seok Kim and Woo-Chan Park
}

\begin{abstract}
Background: Central and lateral lymph node metastases are quite common in patients with papillary thyroid carcinoma, and the predictors for those metastases have been well studied. Right upper paraesophageal lymph node metastasis has rarely been studied. The aim of this study was to identify the clinicopathological characteristics that may be risk factors for right upper paraesophageal lymph node metastasis in patients with papillary thyroid carcinoma.

Methods: This was a prospective observational study of 243 patients with papillary thyroid carcinoma (PTC) who underwent total thyroidectomy and comprehensive central lymph node dissection with or without lateral lymph node dissection between April 2008 and January 2010. The clinicopathologic findings from these patients were investigated and the patterns of lymph node metastasis were analyzed in the patients who had right upper paraesophageal lymph node disease.
\end{abstract}

Results: Of the 243 patients undergoing lymph node dissection, 14 had right upper paraesophageal lymph node metastases. Two of these patients had right upper paraesophageal lymph node metastasis only, without central compartment metastasis. Univariate analysis of clinicopathologic findings showed that right upper paraesophageal lymph node metastasis had significant association with larger primary tumors, multifocal tumors, extrathyroid extension, and lymphatic invasion ( $p<0.05$ for each factor).

Conclusions: Although there were no independent predictors of right upper paraesophageal lymph node metastasis, it can be the only site of metastasis without other compartmental metastasis. Therefore, during surgery for patients with central or lateral lymph node metastases from PTC, it may be helpful to examine the right upper paraesophageal lymph nodes.

Keywords: Paraesophageal lymph node, Thyroid cancer, Papillary thyroid carcinoma

\section{Background}

Papillary thyroid carcinoma (PTC) is the most common form of thyroid cancer. It generally has a favorable prognosis. As PTC tends to recur in a predictable locoregional pattern, appropriate surgical intervention [1] can be expected to increase long-term survival.

Cervical lymph node metastases are quite common in PTC and have been found in $20 \%$ to $50 \%$ of patients.

\footnotetext{
* Correspondence: wcpark@catholic.ac.kr

Department of Surgery, College of Medicine, The Catholic University of Korea, Yeouido St.Mary's Hospital, 62 Yeouido-dong, Youngdeungpo-gu, Seoul 150-713, Korea
}

Lymph node metastases are known to be important prognostic factors for locoregional and distant metastasis [2-4]. Local recurrence in the central compartment after initial surgery has been reported to increase mortality rates [5].

Total thyroidectomy is the standard procedure for all PTC $>10 \mathrm{~mm}$ in size $[3,6]$, but optimum treatment for smaller tumors and indications for lymph node dissection remain controversial. Lymph node metastases generally spread sequentially from the nodes of the central compartment of the neck to the nodes of the lateral compartment, and, in frequently, skip metastasis occurs [7-10]. The central compartment of the neck includes

\section{Biomed Central}


the precricoid (Delphian), pretracheal, and paratracheal lymph nodes. The right upper paraesophageal lymph nodes are difficult to distinguish from the central compartment; however, that section is important, because metastasis to a lateral lymph node can involve the mediastinum and because they are located close to the right recurrent laryngeal nerve [11,12]. The management of right upper paraesophageal lymph node metastases, particularly posterior to the right recurrent laryngeal nerve, remains unclear. Therefore, this study was performed to examine the clinicopathologic factors associated with right upper paraesophageal lymph node metastasis in patients with papillary thyroid carcinoma.

\section{Methods}

A total of 243 consecutive patients with PTC were prospectively enrolled in this study and underwent thyroid surgery plus cervical lymph node dissection at Yeouido St. Mary's Hospital of the Catholic University in Seoul, Korea, between April 2008 and January 2010. All patients underwent preoperative thyroid function tests, thyroid ultrasonography (US), US-guided fine-needle aspiration cytology (FNAC) of the thyroid nodules, and neck computed tomography $(\mathrm{CT})$ for preoperative staging of PTC and evaluation of lymph node status.

Total thyroidectomy and central lymph node dissection were performed with or without lateral lymph node dissection. Surgery was performed when the thyroid nodules detected by US were proven to be papillary carcinoma on FNAC or when the FNAC was suspicious for malignancy. A frozen section biopsy of the thyroid lesion was performed during surgery. If frozen section results confirmed malignancy, total thyroidectomy and comprehensive central lymph node dissection were performed. Lateral lymph node dissection was performed if preoperative imaging studies were suspicious for metastasis, for instance, if the ultrasound image revealed loss of central hilum echogenicity, microcystic changes, or microcalcifications. Neck CT with and without intravenous contrast agent was performed preoperatively, and 5$\mathrm{mm}$ image slices were obtained from the base of the skull to the thoracic inlet. A single radiologist evaluated the images for metastases in the lateral lymph nodes (LNs) of the neck. In patients whose CT scans showed strong enhancement, calcifications, or necrotic or cystic changes after intravenous contrast, lateral lymph node dissection was performed with correlation to the US images.

The central compartment of the neck includes the region between the common carotid arteries and is bounded superiorly by the hyoid bone. The inferior border has been variably defined as the sternal notch or the innominate artery. The paratracheal nodes may be anterior and posterior to the recurrent laryngeal nerves.
These nodes may be found posterior to the common carotid artery on the right because of the anatomic variation of the sides. In this study, dissection of the right upper paraesophageal lymph nodes included the area posterior to the right recurrent laryngeal nerve. The field was inspected for macroscopic disease before dissection. Figure 1 shows the boundaries of the upper paraesophageal area that was dissected.

The histopathology of the thyroid tumor was determined from all biopsy specimens examined by the hospital's pathologists. Pathologic reports were compiled, and clinicopathological characteristics, including tumor size, tumor location, multifocal tumor, tumor encapsulation, extrathyroidal extension, capsular invasion, lymphatic invasion, perineural invasion, vascular invasion, and concurrent thyroiditis were recorded.

Statistical analysis was performed using SPSS, version 18.0 (SPSS Inc., Chicago, IL). Univariate analysis was performed using the chi-square test and Fisher's exact test, and multivariate analysis was performed using logistic regression analysis. Differences were considered significant for $p<0.05$.

This study was reviewed and approved by the institutional review board at Yeouido St. Mary's Hospital.

\section{Results}

The clinicopathologic characteristics of the 243 patients [200 females (82.3\%) and 43 males (17.7\%), mean age 49.54 years] are summarized in Table 1. All patients underwent total thyroidectomy. The mean tumor size

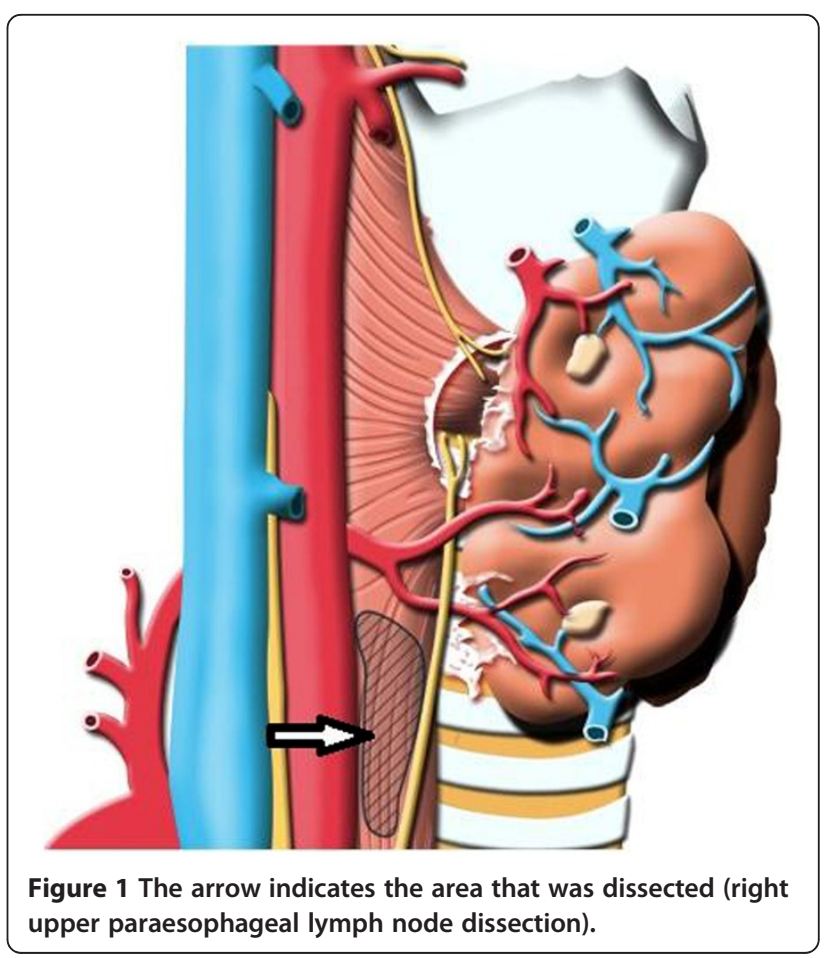


Table 1 Clinicopathologic characteristics of 243 patients who underwent total thyroidectomy and cervical lymph node dissection

\begin{tabular}{|c|c|c|}
\hline Variables & & Results $(n=243)$ \\
\hline \multirow[t]{2}{*}{ Age } & $<45$ & $88(36.2 \%)$ \\
\hline & $\geq 45$ & $155(63.8 \%)$ \\
\hline \multirow[t]{2}{*}{ Gender } & Male & $43(17.7 \%)$ \\
\hline & Female & $200(82.3 \%)$ \\
\hline \multirow[t]{2}{*}{ Tumor size } & $<1 \mathrm{~cm}$ & $128(52.7 \%)$ \\
\hline & $\geq 1 \mathrm{~cm}$ & $115(47.3 \%)$ \\
\hline \multirow[t]{4}{*}{ Tumor location } & Left & $78(32.1 \%)$ \\
\hline & Right & $101(41.6 \%)$ \\
\hline & Isthmus & $6(2.4 \%)$ \\
\hline & Both & $58(23.9 \%)$ \\
\hline \multirow[t]{4}{*}{ Solitary lesion } & Upper & $37(15.2 \%)$ \\
\hline & Middle & $81(33.3 \%)$ \\
\hline & Lower & $43(17.7 \%)$ \\
\hline & Isthmus & $6(2.5 \%)$ \\
\hline \multirow[t]{2}{*}{ Multifocal lesion } & Both lobes & $58(23.9 \%)$ \\
\hline & Affected lobe & $14(5.8 \%)$ \\
\hline \multirow[t]{2}{*}{ Multiplicity } & $(-)$ & $160(65.8 \%)$ \\
\hline & $(+)$ & $83(34.2 \%)$ \\
\hline \multirow[t]{2}{*}{ Extrathyroidal extension } & $(-)$ & $101(41.6 \%)$ \\
\hline & $(+)$ & $142(58.4 \%)$ \\
\hline \multirow[t]{2}{*}{ Node metastasis } & $(-)$ & $123(50.6 \%)$ \\
\hline & $(+)$ & $120(49.4 \%)$ \\
\hline \multirow{2}{*}{$\begin{array}{l}\text { Right upper } \\
\text { paraesophageal metastasis }\end{array}$} & $(-)$ & $229(94.2 \%)$ \\
\hline & $(+)$ & $14(5.8 \%)$ \\
\hline $\begin{array}{l}\text { Retrieved central } \\
\text { lymph nodes }\end{array}$ & Mean $\left(95 \% \mathrm{Cl}^{\mathrm{a}}\right)$ & $8.3210(7.6611-8.9808)$ \\
\hline $\begin{array}{l}\text { Metastatic central } \\
\text { lymph nodes }\end{array}$ & Mean $\left(95 \% \mathrm{Cl}^{\mathrm{a}}\right)$ & $1.5556(1.2071-1.9040)$ \\
\hline $\begin{array}{l}\text { Retrieved lateral } \\
\text { lymph nodes }\end{array}$ & Mean $\left(95 \% \mathrm{Cl}^{\mathrm{a}}\right)$ & $19.8333(17.2426-22.4241)$ \\
\hline $\begin{array}{l}\text { Metastatic lateral } \\
\text { lymph nodes }\end{array}$ & Mean $\left(95 \% \mathrm{Cl}^{\mathrm{a}}\right)$ & $1.9167(1.3089-2.5244)$ \\
\hline
\end{tabular}

${ }^{a} \mathrm{Cl}$ : confidence interval.

was $1.06 \pm 0.60 \mathrm{~cm}$. Tumors were located in the right lobe, left lobe, isthmus, and bilateral lobes in $41.6 \%$, $32.1 \%, 2.4 \%$, and $23.9 \%$ of patients, respectively. There were 37 patients with the primary lesion located in the upper third of the thyroid lobe, 81 patients with lesions in the middle third, and 43 patients with lesions in the lower third. Multifocal tumors were identified in 34.2\% of patients. Positive nodal metastases occurred in $49.4 \%$ of patients. Among the 243 patients who underwent central neck dissection, 14(5.8\%) patients were positive for right upper paraesophageal lymph node metastases.
In 1 of the 14 patients with right upper paraesophageal lymph node metastasis, the other compartments were negative for lymph node metastasis. There was one patient with right upper paraesophageal lymph node metastasis and lateral lymph node metastasis. Eight of the 14 patients had metastasis in the central and lateral compartments. Multifocal lesions (both lobes or single affected lobe) were observed in 8 of 14 patients (Table 2).

Univariate analysis of the clinicopathologic factors associated with metastasis to a right upper paraesophageal lymph node (Table 3) indicated that right upper paraesophageal lymph node metastasis was significantly associated with larger primary tumors, multifocal tumors, extrathyroidal extension, and lymphatic invasion ( $p<0.05$ each factor). Although the number of removed lymph nodes was not statistically significant, the numbers of metastatic central lymph nodes and lateral lymph nodes in the patients with right upper paraesophageal lymph node metastasis were statistically significant. In contrast, age, gender, tumor location, necrosis, vascular invasion, and perineural invasion were not associated with the occurrence of right upper paraesophageal lymph node metastasis. Although there was no statistical significance, a right upper paraesophageal lymph node metastasis originating from a PTC in the contralateral left thyroid lobe occurred in only 1 of 14 patients.

Recurrent laryngeal nerve injury was observed in 6 of 243 patients. Permanent hypoparathyroidism requiring calcium and vitamin D supplementation occurred in 24 (9.9\%) of 243 patients. Postoperative whole-body radioiodine scanning and determination of rhTSH-stimulated serum thyroglobulin concentration were performed in 182 (74.9\%) patients, and no visible iodine uptake was seen outside the thyroid bed. The stimulated thyroglobulin levels were low or undetectable.

Table 2 Status of lymph node metastasis of positive right upper paraesophageal lymph node metastases according to primary tumor location

\begin{tabular}{llcc}
\hline & & Lateral(-) & Lateral(+) \\
\hline Central(-) & Upper & 0 & 0 \\
& Middles & 0 & 1 \\
& Lower & 0 & 0 \\
& Multifocal in both lobes & 1 & 0 \\
& Multifocal in affected lobe & 0 & 0 \\
Central(+) & Upper & 1 & 2 \\
& Middle & 0 & 0 \\
& Lower & 0 & 2 \\
& Multifocalin both lobes & 2 & 0 \\
\hline
\end{tabular}


Table 3 Univariate analysis of the clinicopathologic factors associated with right upper paraesophageal lymphnode metastasis

\begin{tabular}{|c|c|c|c|c|}
\hline & & \multicolumn{2}{|c|}{ Status of right upper paraesophageal lymph node } & \multirow[t]{2}{*}{$p$-Value } \\
\hline & & Metastasis(-) $n=229$ & Metastasis(+) $n=14$ & \\
\hline Age(yrs) & Mean $\left(95 \% \mathrm{Cl}^{\mathrm{a}}\right)$ & $49.51(48.04-50.97)$ & $50.07(41.11-59.03)$ & 0.73 \\
\hline \multirow[t]{2}{*}{ Gender } & Male & 38 & 5 & 0.07 \\
\hline & Female & 191 & 9 & \\
\hline \multirow[t]{3}{*}{ Tumor size } & Mean $\left(95 \% \mathrm{Cl}^{\mathrm{a}}\right)$ & $1.0195(0.9455-1.0938)$ & $1.6429(1.1599-2.1258)$ & 0.006 \\
\hline & $<1 \mathrm{~cm}$ & 125 & 3 & 0.016 \\
\hline & $\geq 1 \mathrm{~cm}$ & 124 & 11 & \\
\hline \multirow[t]{4}{*}{ Tumor location } & Left & 77 & 1 & 0.06 \\
\hline & Right & 95 & 6 & \\
\hline & Isthmus & 6 & 0 & \\
\hline & Both & 51 & 7 & \\
\hline \multirow[t]{4}{*}{ Solitary lesion } & Upper & 34 & 3 & 0.15 \\
\hline & Middle & 80 & 1 & \\
\hline & Lower & 41 & 2 & \\
\hline & Isthmus & 6 & 0 & \\
\hline \multirow[t]{2}{*}{ Multifocal lesion } & Both lobes & 13 & 1 & \\
\hline & Affected lobe & 51 & 7 & \\
\hline \multirow[t]{2}{*}{ Extrathyroidal extension } & $(-)$ & 100 & 1 & 0.009 \\
\hline & $(+)$ & 129 & 13 & \\
\hline \multirow[t]{2}{*}{ Lymphatic invasion } & $(-)$ & 119 & 0 & 0.000 \\
\hline & $(+)$ & 110 & 14 & \\
\hline \multirow[t]{2}{*}{ Multiplicity } & $(-)$ & 156 & 4 & 0.002 \\
\hline & $(+)$ & 73 & 10 & \\
\hline \multirow[t]{2}{*}{ Vascular invasion } & $(-)$ & 219 & 13 & 0.49 \\
\hline & $(+)$ & 10 & 1 & \\
\hline \multirow[t]{3}{*}{ Combined thyroiditis } & $(-)$ & 185 & 13 & 0.39 \\
\hline & Hashimoto thyroiditis & 27 & 0 & \\
\hline & Lymphocytic thyroiditis & 17 & 1 & \\
\hline Retrieved central lymph nodes & Mean $\left(95 \% \mathrm{Cl}^{\mathrm{a}}\right)$ & $8.2664(7.5873-8.9454)$ & $9.2143(6.0666-12.3619)$ & 0.33 \\
\hline Metastatic central lymph nodes & Mean $\left(95 \% \mathrm{Cl}^{\mathrm{a}}\right)$ & $1.3493(1.0205-1.6782)$ & $4.9286(2.5700-7.2872)$ & 0.004 \\
\hline Retrieved lateral lymph nodes & Mean $\left(95 \% \mathrm{Cl}^{\mathrm{a}}\right)$ & 20.08(17.0944-23.0656) & 18.6(13.2234-23.9766) & 0.64 \\
\hline Metastatic lateral lymph nodes & Mean $\left(95 \% \mathrm{Cl}^{\mathrm{a}}\right)$ & $0.2882(0.1709-0.4055)$ & $3.5(1.4029-5.5971)$ & 0.000 \\
\hline
\end{tabular}

${ }^{a} \mathrm{Cl}$ : confidence interval.

\section{Discussion}

The appropriate extent of cervical lymph node dissection in PTC remains controversial [12]. Some authors have concluded that if the tumor is smaller than $10 \mathrm{~mm}$ and the patient belongs to a low-risk group, the good prognosis of these patients allows for conservatives urgical treatment. They have found that extensive lymph node dissection offers no advantage in the treatment of PTC and increases morbidity $[2,13,14]$. Other authors have recommended total thyroidectomy with central lymph node dissection because a high rate of locoregional recurrence and distant metastasis from PTC may decrease survival, and preoperative assessment of the central compartment by US [15-18] is less sensitive than lateral compartment ultrasound.

In this study, total thyroidectomy with comprehensive central lymph node dissection, including right upper paraesophageal lymph node dissection, was performed with or without evidence of lateral lymph node metastases on preoperative US and CT studies.

In general, cervical lymph node metastases are quite common in PTC, having been found in $20 \%$ to $50 \%$ of patients. In this study, $49.4 \%$ of the patients had cervical lymph node metastases. Most series have reported a 
higher rate of nodal disease in the central compartment and lateral neck than in the mediastinum $[7,19]$; however, right upper paraesophageal lymph node metastasis posterior to the right recurrent laryngeal nerve is associated with superior mediastinal lymph node metastasis and is a risk for invasion of the mediastinal organs, including the trachea $[20,21]$. Because it has been associated with a high risk of postoperative hypocalcemia [22], there are currently reduced numbers of indications for elective right upper paraesophageal lymph node dissection. However, reoperative cervical lymph node dissection can be challenging and places the regional lymph nodes and parathyroids at increased risk [5,23]. There may be a higher rate of permanent recurrent laryngeal nerve injury and permanent hypoparathyroidism when cervical lymph node dissection is performed with total thyroidectomy than for total thyroidectomy alone [5].The rate of permanent hypoparathyroidism has ranged from $0 \%$ to $14.3 \%$, and the rate of unintentional recurrent laryngeal nerve injury has ranged from $0 \%$ to $5.7 \%$ [9,16,23-25]. The results of this study were similar. Permanent recurrent laryngeal nerve injury and permanent hypoparathyroidism were found in $2.5 \%$ and $9.9 \%$ of patients, respectively. The morbidity-to-benefit ratio remains unclear for central lymph node dissection, but it can be performed safely by expert surgeons.

Zhang et al. [26] demonstrated that primary tumors arising from the upper lobe of the thyroid spread frequently to the lateral nodes while skipping the central nodes, whereas primary tumors originating from the lower lobe spread directly to the central nodes. Although the study of Zhang et al. was important for the understanding of nodal spreading, our study did not find an association between the location of the primary tumor and metastatic status of neck lymph nodes in patients with right upper paraesophageal lymph node metastasis.

In this study, 14 of 243 patients who underwent thyroidectomy with cervical lymph node dissection had right upper paraesophageal lymph node metastasis. Univariate analysis showed that larger tumor size, multifocal tumors, extrathyroidal extension, and lymphatic invasion were associated with right upper paraesophageal lymph node metastasis. Of the 14 patients, 2 were found with skip metastasis. Two of 14 patients had lymph node metastasis without central compartment metastasis, and 1 of these patients had lateral lymph node metastasis. In these two cases, the tumor size was greater than $2 \mathrm{~cm}$, cancer was observed in both lobes, and extrathyroidal extension was observed. Although there was no statistical significance, a right upper paraesophageal lymph node metastasis originating from a PTC in the contralateral left thyroid lobe occurred in only 1 of 14 patients. The tumor size was $2.4 \mathrm{~cm}$, multifocal cancer was observed in the affected lobe, and extrathyroidal extension was observed. According to the preoperative study and operative findings, if a patient only has cancer in the left thyroid lobe, a right upper paraesophageal lymph node dissection should be performed.

Patients with nodal metastasis from papillary carcinoma of the thyroid have an increased rate of extrathyroidal invasion, locoregional recurrence, and distant metastasis [27-29]. Extrathyroidal extension is also known to be a potent and adverse prognostic indicator $[1,30]$. Lymphatic and vascular invasion are markers of aggression and carry a less favorable long-term prognosis [31-33]. Thus, if thyroid cancer shows these features (multiplicity, extrathyroidal extension) during surgery, it may be necessary to inspect the right upper paraesophageal lymph nodes.

This study has demonstrated that papillary thyroid carcinoma can metastasize, although rarely, solely to the right upper paraesophageal lymph nodes posterior to the recurrent laryngeal nerves. Because of the relatively brief initial follow-up period, local recurrence, distant metastasis, and prognosis were not evaluated. The authors plan on reporting more comprehensive results and ample data, which will be collected during long-termfollow up.

\section{Conclusions}

Right upper paraesophageal lymph node metastasis posterior to the recurrent laryngeal nerves from papillary thyroid carcinoma is fairly uncommon. In univariate analysis, metastasis to these lymph nodes was associated with tumor size, multiplicity, extrathyroidal extension, and lymphatic invasion. The results suggest that for locoregional control, it would be helpful to examine the right upper paraesophageal lymph nodes during surgery for patients with extensive cervical lymph node metastases from PTC.

\section{Competing interests}

The authors declare that they have no competing interests.

\section{Authors' contributions}

WCP: participated in the conception and design of the study and carried out the surgery. YSK: participated in data analysis and interpretation of data drafted the manuscript. All authors read and approved the final manuscript.

\section{Acknowledgments}

This study did not receive grant funding or other subsidies.

Received: 7 March 2012 Accepted: 15 July 2012

Published: 16 August 2012

\section{References}

1. Mazzaferri EL, Jhiang SM: Long-term impact of initial surgical and medical therapy on papillary and follicular thyroid cancer. Am J Med 1994 97:418-428.

2. Grebe SK, Hay ID: Thyroid cancer nodal metastases: biologic significance and therapeutic considerations. Surg Oncol Clin N Am 1996, 5:43-63.

3. Cooper DS, Doherty GM, Haugen BR, Kloos RT, Lee SL, Mandel SJ, Mazzaferri EL, Mclver B, Sherman SI, Tuttle RM: Management guidelines for patients 
with thyroid nodules and differentiated thyroid cancer. Thyroid 2006, 16:109-142.

4. Chow SM, Law SC, Chan JK, Au SK, Yau S, Lau WH: Papillary microcarcinoma of the thyroid-Prognostic significance of lymph node metastasis and multifocality. Cancer 2003, 98:31-40.

5. White ML, Doherty GM: Level VI lymph node dissection for papillary thyroid cancer. Minerva Chir 2007, 62:383-393.

6. Harris PE: The management of thyroid cancer in adults: a review of new guidelines. Clin Med 2002, 2:144-146.

7. Machens A, Hinze R, Thomusch O, Dralle H: Pattern of nodal metastasis for primary and reoperative thyroid cancer. World J Surg 2002, 26:22-28.

8. Qubain SW, Nakano S, Baba M, Takao S, Aikou T: Distribution of lymph node micrometastasis in pNO well-differentiated thyroid carcinoma. Surgery 2002, 131:249-256.

9. Gimm O, Rath FW, Dralle H: Pattern of lymph node metastases in papillary thyroid carcinoma. Br J Surg 1998, 85:252-254.

10. Machens A, Holzhausen HJ, Dralle H: Skip metastases in thyroid cancer leaping the central lymph node compartment. Arch Surg 2004, 139:43-45.

11. Carty SE, Cooper DS, Doherty GM, Duh QY, Kloos RT, Mandel SJ, Randolph GW, Stack BC Jr, Steward DL, Terris DJ: Consensus statement on the terminology and classification of central neck dissection for thyroid cancer. Thyroid 2009, 19:1153-1158.

12. Ferlito A, Rinaldo A, Silver CE, Shaha AR, Fliss DM, Rodrigo JP, Elsheikh MN, Khafif A: Paratracheal node dissection for well-differentiated cancer of the thyroid: indications, technique and results. Auris Nasus Larynx 2008, 35:463-468.

13. DeGroot LJ, Kaplan EL, McCormick M, Straus FH: Natural history, treatment, and course of papillary thyroid carcinoma. J Clin Endocrinol Metab 1990, 71:414-424.

14. Hay ID, Bergstralh EJ, Goellner JR, Ebersold JR, Grant CS: Predicting outcome in papillary thyroid carcinoma: development of a reliable prognostic scoring system in a cohort of 1779 patients surgically treated at one institution during 1940 through 1989. Surgery 1993, 114:1050-1057. discussion 1057-1058.

15. Loh KC, Greenspan FS, Gee L, Miller TR, Yeo PP: Pathological tumor-nodemetastasis (pTNM) staging for papillary and follicular thyroid carcinomas: a retrospective analysis of 700 patients. J Clin Endocrinol Metab 1997, 82:3553-3562

16. Ito Y, Tomoda C, Uruno T, Takamura Y, Miya A, Kobayashi K, Matsuzuka F, Kuma K, Miyauchi A: Clinical significance of metastasis to the central compartment from papillary microcarcinoma of the thyroid. World I Surg 2006, 30:91-99.

17. Moley JF, DeBenedetti MK: Patterns of nodal metastases in palpable medullary thyroid carcinoma: recommendations for extent of node dissection. Ann Surg 1999, 229:880-887. discussion 887-888.

18. Kouvaraki MA, Shapiro SE, Fornage BD, Edeiken-Monro BS, Sherman SI, Vassilopoulou-Sellin R, Lee JE, Evans DB: Role of preoperative ultrasonography in the surgical management of patients with thyroid cancer. Surgery 2003, 134:946-954. discussion 954-945.

19. Noguchi S, Noguchi A, Murakami N: Papillary carcinoma of the thyroid. I. Developing pattern of metastasis. Cancer 1970, 26:1053-1060.

20. Block MA, Miller JM, Horn RC Jr: Significance of mediastinal lymph node metastases in carcinoma of the thyroid. Am J Surg 1972, 123:702-705.

21. Machens A, Hinze R, Lautenschlager C, Thomusch O, Dralle H: Thyroid carcinoma invading the cervicovisceral axis: routes of invasion and clinical implications. Surgery 2001, 129:23-28.

22. Goncalves Filho J, Kowalski LP: Surgical complications after thyroid surgery performed in a cancer hospital. Otolaryngol Head Neck Surg 2005, 132:490-494.

23. Shindo M, Wu JC, Park EE, Tanzella F: The importance of central compartment elective lymph node excision in the staging and treatment of papillary thyroid cancer. Arch Otolaryngol Head Neck Surg 2006, 132:650-654.

24. Tisell LE, Nilsson B, Molne J, Hansson G, Fjalling M, Jansson S, Wingren U: Improved survival of patients with papillary thyroid cancer after surgical microdissection. World J Surg 1996, 20:854-859.

25. Leboulleux S, Rubino C, Baudin E, Caillou B, Hartl DM, Bidart JM, Travagli JP, Schlumberger M: Prognostic factors for persistent or recurrent disease of papillary thyroid carcinoma with neck lymph node metastases and/or tumor extension beyond the thyroid capsule at initial diagnosis. J Clin Endocrinol Metab 2005, 90:5723-5729.

26. Zhang L, Wei WJ, Ji QH, Zhu YX, Wang ZY, Wang Y, Huang CP, Shen Q, Li DS, Wu Y: Risk factors for neck nodal metastasis in papillary thyroid microcarcinoma: a study of 1066 patients. J Clin Endocrinol Metab 2012, 97:1250-1257.

27. Coburn MC, Wanebo HJ: Prognostic factors and management considerations in patients with cervical metastases of thyroid cancer. Am J Surg 1992, 164:671-676.

28. Noguchi S, Murakami N, Yamashita H, Toda M, Kawamoto H: Papillary thyroid carcinoma: modified radical neck dissection improves prognosis. Arch Surg 1998, 133:276-280.

29. Ortiz S, Rodriguez JM, Soria T, Perez-Flores D, Pinero A, Moreno J, Parrilla P: Extrathyroid spread in papillary carcinoma of the thyroid: clinicopathological and prognostic study. Otolaryngol Head Neck Surg 2001, 124:261-265.

30. Lang BH, Chow SM, Lo CY, Law SC, Lam KY: Staging systems for papillary thyroid carcinoma: a study of 2 tertiary referral centers. Ann Surg 2007, 246:114-121.

31. Gardner RE, Tuttle RM, Burman KD, Haddady S, Truman C, Sparling YH, Wartofsky L, Sessions RB, Ringel MD: Prognostic importance of vascular invasion in papillary thyroid carcinoma. Arch Otolaryngol Head Neck Surg 2000, 126:309-312.

32. Furlan JC, Bedard YC, Rosen IB: Clinicopathologic significance of histologic vascular invasion in papillary and follicular thyroid carcinomas. J Am Coll Surg 2004, 198:341-348.

33. Falvo L, Catania A, D'Andrea V, Marzullo A, Giustiniani MC, De Antoni E: Prognostic importance of histologic vascular invasion in papillary thyroid carcinoma. Ann Surg 2005, 241:640-646.

doi:10.1186/1477-7819-10-164

Cite this article as: Kim and Park: Clinical predictors of right upper paraesophageal lymph node metastasis from papillary thyroid carcinoma. World Journal of Surgical Oncology 2012 10:164.

\section{Submit your next manuscript to BioMed Central and take full advantage of:}

- Convenient online submission

- Thorough peer review

- No space constraints or color figure charges

- Immediate publication on acceptance

- Inclusion in PubMed, CAS, Scopus and Google Scholar

- Research which is freely available for redistribution 